\title{
La revitalització de les grans religions: un repte per a l'autocomprensió secular de la modernitat?*
}

\author{
Jürgen Habermas \\ Goethe Universität Frankfurt
}

\section{Resum}

La vitalitat de la religió ha conduït a qüestionar la tesi que vincula la modernització i la secularització. Cal, doncs, repensar el mateix significat de la «modernitat», per tal d'adaptar-la a l'escala mundial. A l'hora de dur a terme un diàleg intercultural ja no es pot confiar en un suposat universalisme de la raó. La raó secular no pot pretendre establir els criteris de la racionalitat sense prendre en consideració també altres tradicions, com les que beuen de la religió. Es planteja, doncs, la pregunta de si el pensament postmetafísic pot aprendre alguna cosa de les tradicions religioses i si, per fer-ho, cal que s'hi relacioni de manera agnòstica.

Paraules clau: secularització; religió; modernitat; democràcia; raó.

\begin{abstract}
The revitalization of religion: a challenge for the secular self-understanding of modernity?
\end{abstract}

The vitality of religion has led to a questioning of the thesis linking modernization and secularization. It is therefore necessary to rethink the meaning of «modernity» itself to adapt it to the global scale. When conducting an intercultural dialogue we cannot trust in a putative universalism of reason anymore. Secular reason cannot be expected to lay down the criteria for rationality without giving due consideration to other traditions, such as those drawing form religion. The question then raises, can postmetaphysical thinking learn something from religious traditions? And in order to do it, does it need to approach them in an agnostic way?

Keywords: secularization; religion; modernity; democracy; reason.

\footnotetext{
* Aquest text va ser publicat originàriament amb el títol: «Die Revitalisierung der Weltreligionen - Herausforderung für ein säkulares Selbstverständnis der Moderne?», a Philosophische Texte: Studienausgabe, Bd. V: Kritik der Vernunft, 2009, 387-407. Traducció de Daniel Gamper (Agraeixo les observacions pertinents de Pere Fabra a la traducció.)
} 


\section{Sumari}

\begin{tabular}{|c|c|}
\hline $\begin{array}{r}\text { 1. Què significa la revitalització } \\
\text { de les grans religions per a una societat } \\
\text { àmpliament secularitzada? }\end{array}$ & $\begin{array}{l}\text { 3. El nivell secular del discurs } \\
\text { intercultural sobre els fonaments } \\
\text { de la justícia política }\end{array}$ \\
\hline Com podem entendre la «modernitat» & 4. L'autocomprensió de la raó secular \\
\hline $\begin{array}{r}\text { des de la perspectiva de la societat } \\
\text { mundial emergent? }\end{array}$ & 5. Agnosticisme disposat a aprendre \\
\hline
\end{tabular}

\section{Què significa la revitalització de les grans religions per a una societat àmpliament secularitzada?}

1) Des dels temps de Max Weber i d'Émile Durkheim, ha romàs llargament incontestable la tesi segons la qual existeix un nexe ben estret entre la modernització progressiva de la societat i una secularització cada cop més àmplia de les consciències de la població. Aquesta tesi es basa en tres consideracions.

En primer lloc, el progrés cientificotècnic promou una comprensió antropocèntrica del món «desencantat», és a dir, un món causalment explicable; i un humanisme científicament il.lustrat no es pot reconciliar facilment amb imatges del món teocèntriques i cosmocèntriques. En segon lloc, les esglésies i les comunitats religioses, en el curs de la diferenciació funcional de subsistemes socials, ja no tenen incidència en el dret, la política i el benestar públic, la cultura, l'educació i la ciència, i es limiten a exercir la seva funció genuïna d'administració dels béns salvífics, privatitzen la pràctica religiosa i, en general, perden significat públic. Finalment, el desenvolupament des de societats agràries fins a societats industrials i postindustrials va tenir com a conseqüència un benestar mitjà més elevat $\mathrm{i}$ una seguretat social creixent, $\mathrm{i}$ amb l'alleujament de les crisis vitals, és a dir, amb la seguretat existencial creixent, desapareix per a l'individu la necessitat profundament arrelada de seguir una pràctica que promet dominar les contingències descontrolades mitjançant una "comunicació» amb un "més enllà» o un poder còsmic. A les societats europees del benestar, així com a Canadà, Austràlia i Nova Zelanda, els lligams religiosos dels ciutadans s'han afluixat gradualment des de la fi de la Segona Guerra Mundial de manera dràstica.

Però, des de fa més de dues dècades, per a la sociologia acadèmica, la tesi de la secularització esdevé controvertida ${ }^{1}$, perquè està sotmesa a la sospita d'haver consolidat simplement una gran narrativa dels llocs comuns culturals de la intelligentsia occidental entre 1870 i $1910^{2}$. En les aigües d'una crítica no del tot infundada a l'estreta perspectiva eurocèntrica, s'ha arribat a parlar fins i tot de la «fi de la teoria de la secularització» ${ }^{3}$. Els Estats Units, amb les seves comunitats de creients d'una vitalitat incommovible i grups solidificats

1. J. Hadden (1987), «Towards desacralizing secularization theory», Social Force, 65, 587-611.

2. D. Martin (2005), «Introduction», a: On Secularization, Burlington, Ashgate Publishing.

3. H. JoAs (2007), «Gesellschaft, Staat und Religion», a: H. JoAs (ed.), Säkularisierung und die Weltreligionen, Frankfurt am Main, Fischer, 9-43. 
de ciutadans religiosament vinculats i actius, que constitueixen alhora la punta de llança de la modernització, van ser considerats durant molt de temps la gran excepció a la tendència secularitzadora. Les lliçons que s'extreuen d'una perspectiva globalment ampliada a unes altres cultures i grans religions ens porten a pensar que els Estats Units són avui més aviat el cas normal.

Des d'aquesta perspectiva revisionista, el desenvolupament europeu que, amb el seu racionalisme occidental, havia de constituir el model per a la resta del món esdevé l'autèntica excepció ${ }^{4}$. Es tracta, sobretot, de tres fenòmens superposats que es concreten per fer la impressió d'una resurgence of religion d'efectes mundials: el desplegament missioner de les grans religions, la seva agudització fonamentalista i la instrumentalització política dels seus potencials violents.

a) Un signe de vitalitat és, abans de res, la circumstància que, en el marc de les comunitats religioses i de les esglésies existents, els grups ortodoxos o, en tot cas, conservadors es troben arreu en l'ofensiva. Això és aplicable a l'hinduisme i al budisme, així com a les tres religions monoteistes. Crida l'atenció sobretot la difusió regional de les religions establertes a l'Àfrica i als països de l'est i del sud-est asiàtics. L'èxit missioner depèn, palesament també, de la variabilitat de les formes d'organització. L'Església mundial multicultural del catolicisme romà s'adapta millor a les tendències globalitzadores que no pas les esglésies protestants constituïdes en els estats nació, que són les grans perdedores. Les que es despleguen de manera més dinàmica són les xarxes descentralitzades de l'islam (sobretot, a l'Àfrica subshariana) i les evangèliques (sobretot, a l'Amèrica Llatina). Es caracteritzen per una religiositat extàtica atiada per figures carismàtiques.

b) Els moviments religiosos que creixen més de pressa, com ara els pentecostals i els musulmans radicals, són els que poden ser més ben descrits com a «fonamentalistes». En el culte que s'hi ret, es conjuminen l'espiritualisme i l'escatologia amb idees morals rígides i creences bíbliques literals. Per contra, des dels anys setanta, els «nous moviments religiosos» que sorgeixen de manera inconstant estan marcats per un sincretisme "californià». Tanmateix, comparteixen amb els evangèlics una forma desinstitucionalitzada de pràctica religiosa. Al Japó, han sorgit, en els últims anys, unes quatre-centes d'aquestes sectes, que barregen elements del budisme i la religió popular amb doctrines pseudocientífiques i esotèriques. A la República Popular de la Xina, les represàlies estatals contra les sectes Falun Gong han dirigit l'atenció al gran nombre de «noves religions», els membres de les quals s'estima que poden ser uns 80 milions 5 .

c) El règim dels mul.làs a l'Iran i el terrorisme islàmic són els exemples més espectaculars d'un desencadenament de potencials religiosos violents.

4. P. L. Berger (2005), «The Desecularization of the World: A Global Overview», a: P. L. Berger (ed.), The Desecularization of the World: Resurgent Religion and World Politics, Grand Rapids, Eerdmans, 1-18.

5. J. Gentz (2007), «Die religiöse Lage Ostasiens», a: H. JoAs (ed.), Säkularisierung und die Weltreligionen, Frankfurt am Main, Fischer, 358-375. 
Sovint, la codificació religiosa atia la brasa de conflictes que tenen un origen profa. Això es pot aplicar a la «dessecularització» del conflicte del Pròxim Orient, així com a la política del nacionalisme hindú i al conflicte incessant entre l'Índia i el Pakistan ${ }^{6}$, o a la mobilització de la dreta religiosa als Estats Units abans i durant la invasió de l'Iraq.

2) No puc entrar en detall en la discussió dels sociòlegs sobre el suposat caràcter excepcional de les societats secularitzades d'Europa en una societat mundial religiosament mobilitzada. Em fa la impressió que les dades comparades globals parlen a favor dels defensors de la tesi de la secularització ${ }^{7}$. Mentre creix la secularització en les societats benestants i desenvolupades, la societat mundial és cada cop més religiosa, ateses les taxes de naixements més altes dels països en vies de desenvolupament. És clar que la propagació dinàmica de la religió no s'explica només per tendències demogràfiques. Una mirada més detallada als contextos en eclosió i a les situacions revolucionàries dels diversos grups que, tanmateix, es troben en una situació d'inseguretat social igual, que són sensibles als missatges d'escenificació populista de les megaesglésies carismàtiques evangèliques, per exemple: a l'Amèrica Llatina, a l'est d'Àsia i a l'Àfrica, confirma la hipòtesi sobre el nexe entre la inseguretat existencial i la necessitat religiosa ${ }^{8}$. Per explicar l'agudització fonamentalista i la instrumentalització política de les religions mundials, també s'ofereixen justificacions que es troben en consonància amb la tesi de la secularitzacióo .

És cert que el desenvolupament de la consciència religiosa als Estats Units no s'adequa, a primera vista, al patró teòric de la secularització progressiva, però Norris i Ingelhart expliquen la vitalitat religiosa de les societats dels Estats Units, d'una banda, demogràficament, per una immigració procedent de societats tradicionals amb orientació religiosa i taxes altes de naixements $\mathrm{i}$, d'altra banda, des del punt de vista socioestructural, referint-se a la debilitat del sistema de seguretat social. Als Estats Units, no hi ha una xarxa social que protegeixi els grups poblacionals, especialment amenaçats i febles, dels riscos socials provocats per un sistema econòmic de capitalisme salvatge, com encara és habitual a Europa.

La debilitat de la teoria de la secularització consisteix més aviat en les conclusions no diferenciades que es palesen en l'ús poc acurat dels conceptes secularització i modernitat. El que és correcte és l'afirmació que les esglésies i les comunitats religioses, seguint la tendència de la diferenciació dels sistemes

6. Cf. les contribucions de H. G. Kippenberg i H. von Stietencron a H. Joas (ed.) (2007), Säkularisierung und die Weltreligionen, Frankfurt am Main, Fischer, 465-507 i 194-223.

7. P. Norris i R. Ingelhart (2004), Sacred and Secular: Religion and Politics Worldwide, Nova York, Cambridge University Press.

8. D. Martin (2005), "Evangelical Expansion in Global Society», a: On Secularization, Burlington, Ashgate Publishing, 26-46.

9. M. Riesebrodt (2000), Die Rückkehr der Religionen: Fundamentalismus und der "Kampf der Kulturen», Munic, C. H. Beck; H. Bielefeldt i W. Heitmeyer (eds.) (1998), Politisierte Religionen, Frankfurt, Suhrkamp. 
funcionals socials, s'han limitat de manera creixent a la funció nuclear de la praxi de cura de les ànimes $i$ han hagut d'abandonar les seves competències més àmplies en altres àmbits socials. Alhora, la pràctica religiosa s'ha reclòs en formes més individuals. L’especificació funcional del sistema religiós es correspon a una individualització de la pràctica religiosa.

José Casanova ha assenyalat amb raó que la pèrdua funcional i la individualització no han de suposar una pèrdua de significat de la religió, ni en l'espai públic polític i en la cultura d'una societat, ni en la conducció personal de la vida $^{10}$. Amb independència del seu pes quantitatiu, les comunitats religioses poden afirmar un «lloc» també en la vida de societats àmpliament secularitzades. La descripció d'una «societat postsecular», en la mesura que «compta amb la pervivència de comunitats religioses en un entorn progressivament secularitzat», s'adiu amb la consciència pública europe ${ }^{11}$. La lectura modificada de la tesi de la secularització no té tant a veure amb la seva substància com més aviat amb previsions sobre el paper futur «de la» religió. La nova descripció de les societats modernes com a "postseculars" es refereix a una transformació de la consciència que explico sobretot a partir de tres fenòmens.

a) En primer lloc, la percepció que els mitjans de comunicació transmeten d'aquests conflictes mundials - que sovint són presentats com a contraposicions religioses - modifica la consciència pública. No cal ni tan sols la presència inquietant dels moviments fonamentalistes i la por davant d'un terrorisme religiosament bastit, per tal que la majoria dels ciutadans europeus percebi la relativitat de la seva pròpia consciència secular en l'escala mundial. Això fa que la convicció laïcista se senti insegura quant a la previsible desaparició de la religió i abandoni el triomfalisme de la comprensió secular del món. La consciència de viure en una societat secular ja no va lligada amb la certesa que la modernització progressiva cultural i social es realitzarà en detriment del significat públic i personal de la religió.

b) En segon lloc, la religió també adquireix més significació en l'interior dels espais públics nacionals. No estic pensant, en primera instància, en la autopresentació mediàtica de les esglésies, sinó en la circumstància que les comunitats religioses adopten, de manera creixent en la vida política de les societats seculars, el paper de comunitats d'interpretación ${ }^{12}$. Poden influenciar la creació de l’opinió i la voluntat públiques sobre temes pertinents amb aportacions rellevants, bé convincents bé inextricables. Les nostres societats cosmovisivament plurals ofereixen a aquestes intervencions una caixa de ressonància sensible, ja que estan cada cop més dividides sobre

10. J. Casanova (1994), Public Religons in the Modern World, University of Chicago Press.

11. J. Habermas (2001), Glauben und Wissen, Frankfurt, Suhrkamp, p. 13. Traducció catalana: "Creure i saber", a: El futur de la naturalesa, humana. Envers una eugenèsia liberal?, Barcelona, Empúries, 2002.

12. Cf. F. Schlüsser Fiorenza (1992), «The Church as a Comunity of Interpretation», a: D. Browning i F. Schlüsser Fiorenza (eds.), Habermas, Modernity and Public Theology, Nova York, Crossroad, 66-91. 
conflictes de valor que han de ser regulats políticament. En la discussió sobre la legalització de l'avortament o l'eutanàsia, sobre preguntes bioètiques relatives a la medicina reproductiva, qüestions de protecció dels animals i l'escalfament del planeta, etc., sobre aquestes matèries i unes altres de semblants, la situació argumentativa és tan complexa que no està de cap manera decidit de bon principi quina part es pot referir a les intuïcions morals correctes.

c) La immigració de treballadors i de refugiats polítics, procedent sobretot de països amb cultures tradicionals, és el tercer estímul d'una transformació de la consciència dels pobles. Des del segle Xvi, Europa va haver d'aprendre a tractar amb les divisions confessionals a l'interior de la cultura i la societat pròpies. La immigració ha suposat que, a les agudes dissonàncies entre diverses religions, s'hi afegissin els reptes d'un pluralisme de formes de vida que és típic de les societats de migració. Els musulmans veïns obliguen els ciutadans cristians a confrontar-se amb pràctiques de fe que els fan la competència. A les societats europees que es troben en un procés dolorós de transformació cap a societats de migració postcolonials, es percep com un repte la coexistència tolerant amb diverses comunitats religioses, en connexió amb el difícil problema de la integració social de les cultures d'immigració. Cal dir que les confessions autòctones augmenten també la seva ressonància gràcies a l'aparició i la vitalitat de comunitats religioses estrangeres. També contribueixen a aconseguir que els ciutadans secularitzats percebin més clarament el fenomen d'una religió que es fa viva en l'espai públic.

La transformació de la consciència que es duu a terme en societats àmpliament secularitzades es refereix, en primer lloc, al vessant pronosticador de la tesi de la secularització, o sigui, a la suposada desaparició de la religió d'un món desencantat. Aquest desplaçament de l'accent recorda el fet que, originàriament, la tesi estava vinculada a una perspectiva de desenvolupament socioevolutiva d'alta volada que avui, amb la mirada global ampliada a la societat mundial multicultural, ha perdut plausibilitat ${ }^{13}$. La manera com valorem el futur de la religió depèn de com jutgem el destí de la modernitat en la seva totalitat.

\section{Com podem entendre la «modernitat» des de la perspectiva de la societat mundial emergent?}

Es tracta d'esbrinar si les múltiples modernitats emergents es limiten a modificar l'aparença de la modernitat o si bé exigeixen una substitució culturalista en els conceptes fonamentals de les teories de la modernització. Avui són essencialment tres les concepcions que competeixen. Vull començar comparant el concepte sistemicofuncionalista de societat mundial amb el plantejament contra-

13. R. Ingelhart i C. Welzel (2005), Modernization, Cultural Change, and Democracy, Cambridge University Press, part I. 
ri del culturalisme radical, per tal d'introduir una tercera concepció que vincula aquestes perspectives teòriques d'una manera molt prometedora.

$\mathrm{Si}$, amb Luhman, es concep la societat mundial com el resultat d'una dinàmica evolutiva, que empeny la diferenciació funcional més enllà de les fronteres de les societats organitzades en estats nacionals, s'imposa la imatge de sistemes funcionals globalment il.limitats ${ }^{14}$. De la mà de la comunicació digital que transcendeix la dimensió espacial en la xarxa mundial i seguint el patró d'un tràfic també accelerat, global i sense fronteres de persones, béns i capital, hi ha uns altres subsistemes, com ara la ciència i la tècnica, la cultura musical i de masses, l'esport i la criminalitat organitzada, el dret, la medicina i l'educació, que travessen sense entrebancs les fronteres estatals i culturals ${ }^{15}$. Després de la darrera onada globalitzadora del sistema comercial, no existeix cap opció de sortida de l'àmbit d'influència del capitalisme. Més aviat, es desenvolupa, en totes les regions del món, la mateixa infraestructura, els mateixos tipus d'habitacles i de xarxes urbanes, sistemes administratius, de salut i educatius semblants, els mateixos mitjans de comunicació de massa, etc.

En contraposició a aquesta lectura del funcionalisme sistèmic, els plantejaments culturalistes sostenen que una mirada fixada en la "civilització» en singular no presta atenció al caràcter propi de les civilitzacions que només fan la seva aparició en plural ${ }^{16}$. A diferència del concepte introduït per la sociologia de «societats» delimitades segons els territoris estatals i que només en aquest marc són capaces d'actuar, entenem les «civilitzacions» com a enormes formacions històriques que abracen diverses societats des del punt de vista sincrònic i diacrònic. Es mantenen unides per tradicions fortes i s'estructuren de manera difusa vers el centre i la periferia. En la lectura de Toynbee (o també de Spengler), els cercles culturals o les civilitzacions són clarament objectivades com a grans subjectes holísticament constituïts, tot imitant les societats d'organització estatal. Subjectes que es distingeixen recíprocament com a totalitats i com a actors col-lectius en la mesura en què existeixen els uns al costat dels altres sense relacionar-se, «topant violentament entre ells». En contraposició amb l'estratègia conceptual generalitzadora de la teoria social, la comprensió essencialista de les "cultures" tancades en si mateixes (com en el cas de Huntington ${ }^{17}$ ) alimenta la idea particularista de relacions entre amic i enemic i el clash of civilizations.

Cap d'aquestes lectures oposades pot ajustar-se a un fenomen essencial de la modernitat actual: la diversitat dels rostres que «la» modernitat globalitzada, partint dels impulsos occidentals, adopta en altres regions del món. D’una

14. N. Luhman (1975), «Die Weltgesellschaft», a N. Luhman, Soziologische Aufklärung 2: Aufs̈̈tze zur Theorie der Gesellschaft, Opladen, Westdeutscher Verlag, 51-77; R. STICHWEH (2000), Die Weltgesellschaft, Frankfurt, Suhrkamp.

15. STICHWEH (2000).

16. J. P. Arnason (2003), «The rediscovery of civilizations», a: Civilizations in Dispute, Londres, Routledge, cap. 1.

17. S. P. Huntington (1996), The Clash of Civilization and the Remaking of World Order, Nova York, Simon \& Schuster. 
banda, el culturalisme radical és cec per a la difusió global dels sistemes funcionals que segueixen en cada cas la seva pròpia lògica en qualsevol context. El mercat obliga tots els empresaris, inversors i consumidors a ponderar de manera utilitarista els béns $\mathrm{i}$ el càlcul de la maximització del benefici, ja sigui a l'Àfrica, a l'Àsia o a l'Amèrica Llatina. El funcionalisme sistèmic, d'altra banda, només veu els efectes anivelladors de les tendències evolutives generals. En efecte, altres civilitzacions reaccionen als impulsos occidentals cap a la modernització de les seves societats com a reptes als quals han de buscar resposta recorrent als seus propis recursos culturals. Això es deu al fet que la mateixa tensió dialèctica entre tradició $i$ modernitat, de la qual prové la forma occidental de la modernitat, també opera en altres complexos civilitzadors. Això es posa de manifest especialment en les cultures de l'Àsia oriental. Les pròpies tradicions creadores d'identitat no només deixen el seu senyal en l'estil de la comunicació i en la inequívoca fisonomia del món de la vida, sinó també en la institucionalització de la burocràcia de l'Estat i el tràfic mercantil, l'arquitectura i la planificació de les megaurbs, els costums educatius i el currículum escolar, la ponderació del treball, el consum i el temps lliure, l'esport i la salut, etc.

Aquestes observacions de la investigació comparada sobre civilitzacions han conduït Eisenstadt a promoure un interessant programa de recerca ${ }^{18}$. Proposa la imatge d'una societat mundial multicultural a partir del concepte d'una formació civilitzadora pròpia que, a través de la seva dinàmica modernitzadora global, s'ha desconnectat de manera uniforme de totes les altes cultures tradicionals (àdhuc la cultura d'Occident). La perspectiva universalitzadora de la teoria social és combinada amb la mirada diversificadora de la recerca comparada de civilitzacions ${ }^{19}$. Sobre la base d'una única infraestructura social globalitzada (caracteritzada sobretot per uns trets propis sistèmics de dominació cientificotècnica de la natura i del món, exercici burocràtic del poder i creació capitalista de riquesa), «la modernitat» constitueix quelcom com l'arena en la qual es troben les diverses civilitzacions seguint una forma més o menys específicament cultural de la infraestructura comuna. Aquestes civilitzacions es confronten i discuteixen sobre l'autocomprensió de la modernitat, sobre la qual cadascuna sosté versions diferents.

$\mathrm{La}$ «modernitat» va sorgir a Occident com un concepte cultural $^{20}$ que es refereix a una base social, percebuda com a radicalment nova, de relacions vitals revolucionades, un concepte que, al seu torn i gràcies al poder de definició que té, codetermina aquestes relacions ${ }^{21}$. De manera semblant, Arnason veu la modernitat actual globalitzada, sorgida d'arrels multiculturals, com a camp de batalla per a la discussió sobre les definicions d'una base social comuna. Aquesta

18. J. P. Arnason, S. N. Eisenstadt i B. Wittrock (eds.), Axial Civilizations and World History, Leiden, Brill.

19. Arnason (2003), 42.

20. H. R. Jauss (1964), "Ursprung und Bedeutung der Fortschrittsidee in der "Querelle des Anciens et des Modernes"", a H. Kunn i F. Wiedman (eds.), Die Philosophie und die Frage nach dem Fortschritt, Munic, Pustet, 51-72.

21. J. Habermas (1985), Der philosophische Diskurs der Moderne, Frankfurt, Suhrkamp. 
discussió, al mateix temps, no deixa incòlume aquesta base i és la causa de certa fragmentació cultural de la societat mundial ${ }^{22}$.

Però la imatge d'un món culturalment dividit $\mathrm{i}$, per tant, no completament integrat, ens oculta el fet que els conflictes interpretatius que són traslladats al nivell de les polítiques culturals identitàries, no fan res més que dissimular provisionalment el repartiment global desigual del benestar i del poder, com també el darwinisme social guiat per interessos en la política mundial. En tot cas, observem un desenvolupament esperançador en direcció contrària, encara que sigui dèbil. L'espessiment d'una xarxa d'organitzacions internacionals desvia l'atenció a una dimensió fins ara obviada en el concepte de societat mundial. Amb aquesta altra dimensió d'una juridificació progressiva de les relacions internacionals, el concepte d'una societat mundial culturalment dividida situa la qüestió de la secularització sota una altra llum.

En el nostre context, l'interessant són sobretot els pressupòsits cognitius que s'haurien de complir per tal que s'aconseguís una entesa intercultural sobre els principis de justícia política per a una societat mundial multicultural. La resposta abstracta és evident: totes les parts haurien d'estar disposades, amb independència del seu rerefons cultural, a sospesar, des de la pròpia perspectiva i des de la de l'altre participant simultàniament, els punts controvertits, i també en les qüestions pràctiques, a utilitzar només els arguments que siguin convincents en principi per a tothom, amb independència del seu rerefons de conviccions metafísiques o religioses. Aquests pressupòsits cognitius caracteritzen en el seu resultat un nivell d'entesa que neutralitza les cosmovisions i que és, en aquest sentit, secular. Des d'aquest punt de vista, la discussió sobre la secularització pren una altra direcció.

\section{El nivell secular del discurs intercultural sobre els fonaments de la justícia política}

La qüestió ja no és si, en condicions modernes de vida, la religió desapareix dels caps dels ciutadans o sobre si perd rellevància pública. El que de moment trobem a l'arena global són religions mundials d'una vitalitat sense minva. Simultàniament, ja només existeixen societats modernes que confronten, de manera inevitable, els seus membres amb determinats fets fonamentals:

- Amb la pressió individualitzadora i racionalitzadora que exerceix l'economia capitalista i la dominació burocràtica sobre les habituals condicions de vida tradicionals.

- Amb els discursos institucionals del dret, l'economia i la ciència, que creen un saber mundà.

- Amb el pluralisme de concepcions del món i formes de vida que representen alternatives a les pròpies creences i costums de cada cas. 
Avui, la pregunta sobre la relació entre modernització i secularització es planteja d'una altra manera: l'autocomprensió d'una cultura qualsevol que s'ha de confrontar amb aquests fets fonamentals, pot resistir la pressió d'un distanciament reflexiu de si mateixa? Les civilitzacions que es troben en el camí de la modernitat multicultural, podran transformar el seu encuny religiós originari, de manera que es proveeixin del potencial cognitiu per aconseguir desacoblar les conviccions universalment acceptables i, en aquest sentit, «seculars», de les descripcions i els arguments propis de cada cosmovisió? Acceptat això: es desplaçaria la societat mundial multicultural cap a la diferenciació funcional d'una religió que manté la seva rellevància pública sense perjudicar els fonaments legitimadors seculars i independents propis de la política i el dret?

Només amb aquests pressupòsits, tindrien una oportunitat les tendències que assenyalen ${ }^{23}$ cap a una constitucionalització del dret internacional ${ }^{24}$. Si, per contra, els «realistes» tinguessin raó en la seva concepció que, atès el tancament semàntic de les imatges del món incommensurables, és impossible quelcom semblant a la «justícia entre nacions», aleshores, en el millor dels casos, es podria aconseguir una concepció de l'ordre mundial a la manera de Carl Schmitt, segons la qual una prohibició d'intervenció dels "poders no territorials» pacifica un món dividit en "grans espais» imperials ${ }^{25}$.

A més, hem d'evitar el prejudici segons el qual seria sobretot cosa de les esglésies i de les comunitats religioses el fet de participar en discursos interculturals i aprendre'n. Suposem contrafacticament que totes les comunitats religioses ja haguessin utilitzat la reflexivitat present en les formes de vida modernes per aportar una entesa sobre les condicions normatives d'una coexistència global partint del mateix respecte per a tothom. En aquest procés, certament laboriós, interromput per molts contratemps, que conduiria finalment a l'acceptació de regles i procediments d'un dret internacional constitucionalitzat, a través d'un incessant dissens sobre la correcta autointerpretació de la modernitat, s'hauria destriat un tipus específic d'arguments, és a dir, els arguments conceptuals i empírics, científics, morals i jurídics, que (atès el rerefons d'experiència de les condicions modernes de vida) haurien semblat plausibles a totes les parts, amb independència de les seves contraposicions cosmovisives. En un primer pas, podem anomenar «raó secular» la capacitat de desenvolupar i reconèixer arguments com aquests.

Però aquesta imatge és incompleta en un sentit essencial, ja que, en el nostre experiment mental, només hem pres en consideració fins ara comunitats

23. S. Leibfried i M. Zürn (eds.) (2005), Transformation of the State, Cambridge University Press, i l'estudi subsegüent: A. Hurrelmann, S. Liebfried, K. Martens i P. Mayer (eds.) (2008), Zerfasert der Nationalstaat?, Frankfurt, Campus.

24. Per a un esbós d'una societat mundial políticament constituïda, cf. també la meva rèplica a: P. Niesen i B. Herbroth (eds.) (2007), Anarchie der kommunikativen Freiheit: Jürgen Habermas und die Theorie der internationalen Politik, Frankfurt, Suhrkamp, 406-459, esp. $442 \mathrm{~s}$.

25. C. Sснмітт (1991), Völkerrechtliche Großraumordnung, Berlín, Duncker \& Humblot, 1941, i C. Sснмітт (1997), Der Nomos der Erde im Völkerrecht des Jus Publicum Eropäum, Berlín, Dunker \& Humblot, 1959. 
religioses, o en tot cas partits, que es diferencien mútuament en les seves mentalitats pel rerefons religiós característic de la seva cultura de procedència. Tanmateix, no és només necessària una entesa entre cultures de tall religiós. Hi ha un altre tipus de dissens que cal superar i que existeix entre ciutadans seculars $i$ religiosos i elits, i que travessa avui ja les societats civils de tots els països. Aquestes parts disputen sobre la comprensió de la raó secular mateixa.

Els partidaris de tradicions fortes i de doctrines comprehensives es podrien posar d'acord (a la manera d'un overlapping consensus com el proposat per Rawls) sobre els principis per construir un ordre just amb l'ajut d'arguments que es palesarien com a cosmovisivament neutres. Però aquests serien arguments que no es dirigirien contra la pretensió de veritat de la religió i la metafísica. I això perquè, per als creients, els arguments adquireixen força de convicció a partir de la seva connexió amb les premisses de la imatge del món de què en cada cas es tracti; s'adapten com un mòdul a totes les imatges del món possibles $^{26}$. Per contra, les persones que nodreixen la seva comprensió del món i de si mateixes a partir només de raons i d'informacions seculars tenen una comprensió menys restrictiva de la raó secular. Per a ells, la «raó» no és el mínim comú denominador que roman en la competència entre cosmovisions, sinó una autoritat de propi $\mathrm{dret}^{27}$. Mentre que, des de la perspectiva religiosa, el bagatge d'arguments seculars és, d'entrada, tan limitat que no sorgeixen dissonàncies cognitives per al creient, des de la perspectiva secular, la raó és autònoma en la determinació del que en cada cas pot valer com a bon o mal argument.

Això no ha de portar necessàriament a un judici avaluador sobre la intenció moral i el potencial contingut de veritat de les afirmacions religioses o metafísiques, sinó que permet practicar un agnosticisme contingut. D'altra banda, una aguda reserva lä̈cista respecte de les doctrines profetiques i les imatges del món metafísiques, tant a l'interior de la pròpia cultura com a nivell mundial, pot conduir a un conflicte entre creients i secularistes tan profund com el que es dóna entre diverses concepcions del món. Si la banda secular exclou els ciutadans religiosos del cercle dels coetanis moderns i els contempla com si fossin exemplars d'una espècie en extinció, ataca la substància de la pertinença igualitària a l'univers de les persones raonables. Sense un reconeixement recíproc, no es pot garantir la igualtat jurídica formalment assegurada entre ciutadans de l'estat o ciutadans del món com a modus vivendi. En una altra banda, he desenvolupat el que això significa per a l'estabilitat d'un estat constitucional des del punt de vista de la teoria política ${ }^{28}$. En el context de la tesi de la secularització, es tracta de la diferència entre una comprensió laica i una de laïcista de la raó autònoma.

26. J. Rawls (1993), Political Liberalism, Nova York, Columbia University Press, $12 \mathrm{s.}$

27. J. Habermas (1996), "Vernünftig" versus "Wahr" oder die Moral der Weltbilder», a Die Einbeziehung des Anderen, Frankfurt, Suhrkamp, 95-127.

28. J. Habermas (2005), «Religion in der Öffentlichkeit. Kognitive Voraussetzungen für den "öffentlichen Vernunftgebrauch" religiöser und säkularer Bürger», a: Studienausgabe, vol. 4, 259-297. 
He completat el concepte de societat mundial, propi de la teoria de la civilització, amb un nivell cognitiu comú que permet establir una entesa intercultural sobre el que pot comptar com a «justícia entre nacions». Però per assolir aquesta integració no només es necessita, com ara veiem, que totes les comunitats religioses s'aventurin en el correcte processament reflexiu dels fets bàsics de la modernitat, en lloc de cedir a la temptació fonamentalista de retirar-se del món modern o de lluitar-hi en contra. En les societats postseculars, es tracta, més aviat, d'un procés d'aprenentatge complementari que qüestioni l'autocomprensió laïcista d'una raó secular anquilosada en si mateixa. I així arribo al nucli del tema.

\section{L'autocomprensió de la raó secular}

L'autocomprensió secular del pensament postmetafísic té, en primer lloc, el sentit negatiu d'una renúncia a les premisses que provenen de revelacions divines i doctrines profetiques. Però l'autonomia de la raó no només recolza en la diferència entre la lumen naturale i la sacra doctrina. Indica, més aviat, que la fe no pot aportar res més al saber del món. El pensament secular va assolir una determinació positiva en el curs d'una reflexió:

- Sobre el nou tipus de coneixement de la natura que es va formar des del segle XVII.

- Sobre la nova experiència de la pèrdua de la innocència que es va iniciar tot seguint el progrés del coneixement en les ciències naturals, socials i de l'esperit.

Aquest vincle de totes les ciències modernes amb la tradició il.lustrada esperona la crítica de la religió. Així, a Occident, la crítica basada en les ciències de la naturalesa afecta sobretot les creences bíbliques creacionistes, mentre que la recerca històrica amb la seva crítica de fonts apunta al cor de la tradició bíblica. En comparació amb aquests afronts, els efectes de la sociologia i l'antropologia de la religió, que promouen una comprensió funcionalista de la religió, tenen una naturalesa més indirecta.

Sigui com sigui, des de la perspectiva postmetafísica, la competició entre doctrines religioses o imatges cosmològiques del món no admet cap més decisió racional. D’aquí que el fet del pluralisme de cosmovisions esdevingui l'impuls per a la fonamentació d'una moral autònoma de respecte igual per a tothom, basada només en la raó. Només "compten» les afirmacions que poden convèncer, amb independència del context cosmològic o teològic en què arrelen i que, en el seu moment, les feia ser veritables.

La raó constructiva, que genera tots els continguts normatius a partir de si mateixa, troba en Kant la veu d'una visió de la humanitat que unifica una cultura il.lustrada i basada en el saber amb una organització justa de la societat que assegura la pau i la llibertat. Aquest esperit humanista inspira, juntament amb el dret racional, també l'Estat secular que garanteix la llibertat religiosa. 
Des del segle Xvir, la filosofia es manté allunyada, pel que fa als continguts, de la religió, en la mesura en què proporciona llibertat de moviment a les confessions en l'àmbit polític. En la mesura en què es prepara per establir una relació amb la religió com una figura de l'esperit, la filosofia no s'apropa a l'altre estrany en un pla d'igualtat, car és patrimoni del pensament filosòfic determinar què és raonable i què és irraonable en els continguts de les tradicions religioses. Naturalment, per al creient, una religió «reduïda als conceptes» com aquesta, incorporada a la filosofia, ja no és una religió.

La autocomprensió humanística de la modernitat no ha estat només qüestionada històricament per l'imperialisme colonial del segle XIX i les catàstrofes del segle xx. Des que Hegel va descobrir l'herència religiosa en el cor de la filosofia, també s'ha modificat l'autocomprensió filosòfica de la Il-lustració. Certament, el dret racional modern no va sorgir fins que es va donar una confrontació crítica amb el dret natural cristià. Però, una mirada acurada als inicis de l'escolàstica espanyola tardana mostra que podia alimentar-se alhora de l'universalisme igualitari, que es deriva del concepte «d'home» a imatge de Déu ${ }^{29}$. Els conceptes moderns de la persona individual i de la individualització historicovital extreuen les seves connotacions de la unicitat, del caràcter insubstituïble i de la interioritat de les representacions bíbliques d'una vida responsable conduïda sota la mirada de Déu ${ }^{30}$. I la moral del mateix respecte per a tothom fonamentada secularment manté el caràcter categòric d'obligacions incondicionalment vàlides, perquè aquí la perspectiva divina del Judici Final deixa en el «punt de vista moral» les traces d'una transcendència intramundana.

Aquests exemples il.lustren una herència que recull el pensament postmetafísic a partir de la simbiosi ja realitzada a l'edat mitjana del pensament cristià amb la metafísica grega. La filosofia moderna conserva, no obstant això, impulsos directes de les tradicions escatològiques i apocalíptiques, quan, ampliant el seu catàleg de comeses clàssiques, s'enfronta al repte de reflexionar, en termes de diagnosi de l'època, sobre el que és nou dels «nous temps». El discurs filosòfic de la modernitat que, després del descobriment del Nou Món va començar amb el disseny d'utopies socials i que, al llarg del segle XvıII, va adquirir continuïtat en el pensament historicofilosòfic i teoricosocial s'alimenta de motius i d'estímuls de procedència bíblica. La consciència actual de la crisi presta a la crítica la nova dimensió escatològica. El concepte d'emancipació carrega una llibertat entesa igualitàriament amb la dinàmica del pensament històric crític de la dominació. L'apel.lació a una fraternitat i solidaritat que abasta tothom viu del record d'una vida comunitària en què els creients estan agermanats més enllà dels espais i dels temps.

La posició polèmica de la Illlustració respecte del poder mundà de la religió impedeix de veure el fet que el pensament postmetafísic ha transformat

29. E.-W. BöcKenförde (2002), Geschichte der Rechts- und Sozialphilosophie, Tübingen, Antike und Mittelalter, 212-370, i T. STEIN (2007), Himmlische Quellen und irdisches Recht, Frankfurt, Campus.

30. J. Habermas (1988), «Individuierung durch Vergesellschaftung: Zu George Herbert Meads Theorie der Subjektivität», Studienausgabe, 1, 243-302. 
continguts de la tradició judeocristiana que no són menys importants que l'herència de la metafísica. La circumstància no afecta el caràcter secular d'aquest pensament, com ja ho demostra la inversió antropocèntrica de la perspectiva teocèntrica. En el nostre context, és rellevant l'altra circumstància, a saber, que la filosofia pràctica sobre la base d'un ateisme metòdic ha recuperat continguts cognitius a partir de veritats revelades religioses i salvífiques, i que les ha inclòs en la pròpia argumentació. Es consideren «cognitius» els continguts semàntics que es deixen "traduir» en un discurs que s'ha alliberat de l'efecte entorpidor de la «revelació». En aquest discurs, només valen les raons «públiques», és a dir, les que poden convèncer més enllà d'una comunitat particular de fe.

Del fet que el pensament postmetafísic s'hagi deixat inspirar per continguts religiosos no se segueix cap debilitació de les fronteres entre fe i saber. Fins i tot si els continguts semàntics poden travessar aquesta frontera sota circumstàncies diferents, totes dues maneres de considerar la veritat romanen incòlumes. En cada cas, les afirmacions recolzen en una base justificadora diferent $\mathrm{i}$ es vinculen a pretensions de validesa que es distingeixen mútuament pel seu tipus i extensiós ${ }^{31}$.

\section{Agnosticisme disposat a aprendre}

Vull concloure amb la pregunta sobre què pot aprendre la raó secular de la consciència de la seva connexió genealògica amb l'herència judeocristiana. Hegel, com cap altre filòsof, va saber alliberar en el gresol de la dialèctica els continguts de la doctrina cristiana del seu encapsulament dogmàtic originari i, de l'experiència d'aquest procés d'aprenentatge, en va extreure una conseqüència autoconscient. Va concebre la religió completament com a «pensament representatiu» $i$ la va aprofitar per a la filosofia per tal que aquesta pogués decidir què és veritat i què no és veritat en la religió. D’aquesta manera, es pressuposa, certament, que la religió és essencialment un fenomen del passat i que la filosofia no en pot aprendre res més. Però, podem estar segurs que el procés d'apropiació discursiva de continguts religiosos s'ha clos? Des de Kierkegaard fins a Benjamin, Levinas i Derrida, hi ha hagut, una vegada rere l'altra, «escriptors religiosos» que, amb independència de la seva disposició personal, han aportat continguts religiosos al pensament secular.

¿Pot el pensament postmetafísic, mancat del concepte teòric fort de Hegel, excloure que les tradicions religioses contenen potencials semàntics que (si revelen continguts de veritat profans) despleguen una força inspiradora per a tota la societat? Sense perjudicar la seva autocomprensió secular, pot el pensament postmetafísic relacionar-se amb la religió de manera simultàniament disposada a aprendre $i$ agnòstica? La fe conserva quelcom opac pel pensament, que no pot ser ni negat ni merament acceptat. La raó secular consisteix en la

31. Sobre la qüestió de les «pretensions religioses de validesa», cf. E. Arens (2007), Gottesverständigung, Friburg, Herder, 239 s. 
diferència entre certeses de fe i pretensions de validesa públicament criticables, però té reserves de fer una teoria que judica sobre la raonabilitat o la irraonabilitat de la religió en la seva totalitat ${ }^{32}$.

Jürgen Habermas, nascut a Düsseldorf el 28 de juny de 1929, és filòsof i sociòleg pertanyent a la tradició de la teoria crítica de l'Escola de Frankfurt. En els seus escrits, hi ha tractat els problemes epistemològics de les ciències socials a partir del "gir lingüístic» de la filosofia contemporània, ha estudiat els reptes de les societats industrials en el capitalisme, el paper de les institucions des del punt de vista del diàleg i l'emancipació en relació amb la crisi de legitimitat que amenaça els fonaments de les democràcies contemporànies, i els mecanismes de formació del consens polític. Entre les seves obres, cal destacar les següents: La modificació estructural de l'espai públic (1962), Coneixement i interès (1968), Teoria de l'acció comunicativa (1981), Facticitat i validesa (1992), El futur de la naturalesa humana (2001) i Entre naturalisme i religió (2005).

Jürgen Habermas (born in Düsseldorf on 28 July, 1929) is a philosopher and sociologist belonging to the tradition of the critical theory of the Frankfurt School. He has published works on the epistemological problems emerging in social science since the "linguistic turn" in contemporary philosophy, and has studied the challenges of industrial societies in capitalism, the role of institutions - from the point of view of dialogue and emancipation - with regard to the legitimacy crises that affects the foundations of contemporary democracy, and the mechanisms of political consensus-building. Some notable works of his are The Structural Transformation of the Public Sphere (1962), Knowledge and Human Interests (1968), The Theory of Communicative Action (1981), Between Facts and Norms: Contributions to a Discourse Theory of Law and Democracy (1992), The Future of Human Nature (2003) and Between Naturalism and Religion: Philosophical Essays (2008).

32. Sota una premissa semblant va participar Karl Jaspers en el seu diàleg amb Rudolf Bultmann. A dir veritat, no comparteixo la valoració relativitzadora de la diferència entre les ciències i un pensament postmetafísic que, adoptant la forma d'una «fe filosòfica», es troba en un pla d'igualtat amb les doctrines religioses. Cf. K. JasPERS (1962), Der philosophische Glaube angesichts der Offenbarung, Munic, Piper. Referent a aquesta qüestió, vegeu J. Habermas (1997), «Vom Kampf der Glaubensmächte», a: Vom sinnlichen Eindruck zum symbolischen Ausdruck, Frankfurt, Suhrkamp, 9-40. 